\title{
Aqueous Photo-Living Radical Polymerization of Sodium Methacrylate Using a Water-Soluble Nitroxide Mediator
}

\author{
Eri Yoshida \\ Department of Environmental and Life Sciences, Toyohashi University of Technology, 1-1 Hibarigaoka, Tempaku-cho, \\ Toyohashi, Aichi 441-8580, Japan \\ Correspondence should be addressed to Eri Yoshida, eyoshida@ens.tut.ac.jp
}

Received 2 March 2012; Accepted 22 March 2012

Academic Editors: B. Hazer, A. V. Popov, D. Radic, and C. T. Ratnam

Copyright ( 2012 Eri Yoshida. This is an open access article distributed under the Creative Commons Attribution License, which permits unrestricted use, distribution, and reproduction in any medium, provided the original work is properly cited.

The aqueous photo-living radical polymerization of sodium methacrylate (NaMA) was attained using 2,2'-azobis $\{2$-methyl- $N$ [1,1-bis(hydroxymethyl)-2-hydroxyethyl]-propionamide\} (V-80) as the initiator and 4-hydroxy-2,2,6,6-tetramethylpiperidine-1oxyl (HTEMPO) as the mediator in the presence of (4-fluorophenyl)diphenylsulfonium triflate (FS). The polymerization was carried out in water at room temperature by irradiation using a high-pressure mercury lamp. Whereas the polymerization by $\mathrm{V}-80$ and/or FS in the absence of HTEMPO produced polymers with very high molecular weights and broad molecular weight distributions, the HTEMPO-mediated polymerization provided still lower-molecular-weight distributions using both V-80 and FS. The first-order time-conversion plots had an induction period up to $2.5 \mathrm{~h}$; however, they thereafter showed a linear increase. The conversion-molecular weight plots also exhibited a linear correlation. A linear correlation was also obtained for the plots of the molecular weights versus the reciprocal of the initiator concentration. Based on these three correlations, it was found that the HTEMPO-mediated photopolymerization proceeded by a living mechanism.

\section{Introduction}

Poly(sodium methacrylate) (PNaMA), a water-soluble polyelectrolyte, has been used for many objectives, such as surface modification of the wettability and friction [1], suppression of cell adhesion and protein adsorption $[1,2]$, and self-assembly studies on amphiphilic block copolymers in aqueous media [3-7]. While PNaMA and its copolymers were prepared through the living anionic or living radical polymerizations of methacrylates with protecting groups of tert-butyl and benzyl, followed by deprotection [3-7], those were also directly obtained by the controlled/living radical polymerization of sodium methacrylate (NaMA) in water. For instance, the atom transfer radical polymerization (ATRP) of NaMA produced PNaMA with a well-controlled molecular weight [8]. This aqueous ATRP was used for the preparation of polymer brushes including PNaMA segments on gold $[9,10]$ and glass [11] surfaces. The photo-iniferter polymerization using a dithiocarbamate catalyst also succeeded in fabricating a PNaMA-branched graft copolymer on glass [12] and a poly(ethylene terephthalate) film [1].
In recent years, the nitroxide-mediated photo-controlled/living radical polymerization has been established for methyl methacrylate (MMA) using the derivatives of 2,2,6,6-tetramethylpiperidine-1-oxyl (TEMPO) in the presence of the photo-acid generator (PAG) of diaryliodonium hexafluorophosphate [13-17], triarylsulfonium triflate [18$22]$, and an iron-arene complex [23]. This polymerization was used for the photodispersion polymerization of MMA in an alcoholic medium that produced monodispersed microspheres [24].

It was found that the nitroxide-mediated photocontrolled radical polymerization could be used for the NaMA polymerization in water using the water-soluble mediator and PAG. This paper describes the photoliving radical polymerization of NaMA in an aqueous medium using 4-hydroxy-TEMPO (HTEMPO) as the mediator, (4-fluorophenyl)diphenylsulfonium triflate (FS) as the water-soluble PAG, and 2,2'-azobis\{2-methyl-N-[1,1bis(hydroxymethyl)-2-hydroxyethyl]propionamide $\quad$ (V-80) as the initiator. 
<smiles>CC1(C)CC(O)CC(C)(C)N1[O-]</smiles>

HTEMPO

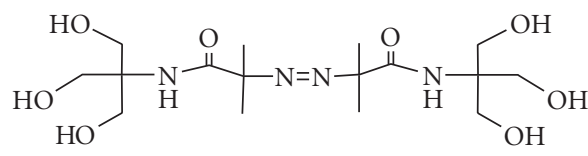

$\mathrm{V}-80$

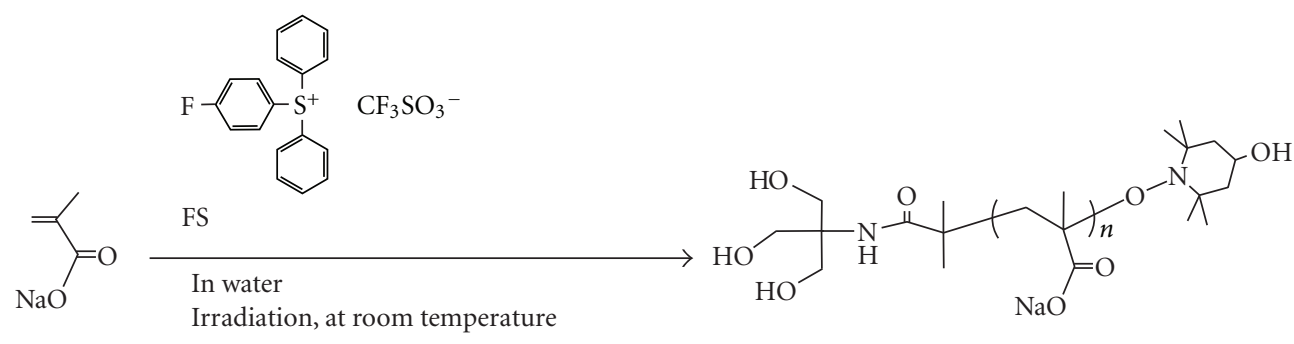

NaMA

PNaMA

Scheme 1: The HTEMPO-mediated photopolymerization of NaMA in the presence of V-80 and FS.<smiles>C=C(C)C(=O)OC(=O)C(C)(C)N=NC(C)(C)NC(=O)C(C)(C)NC(=O)C(CO)(CO)NC(=O)C(C)(C)NC(CO)(CO)CO</smiles>

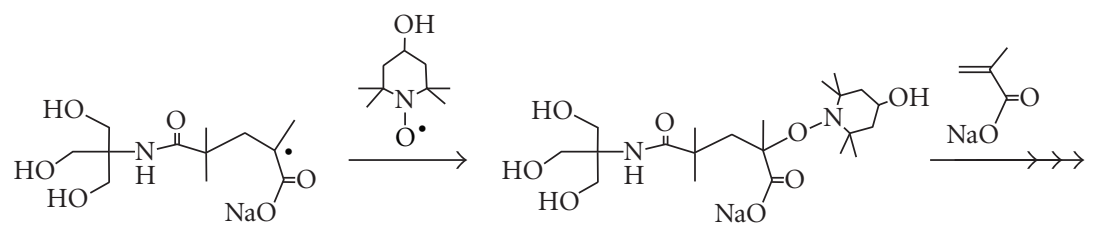

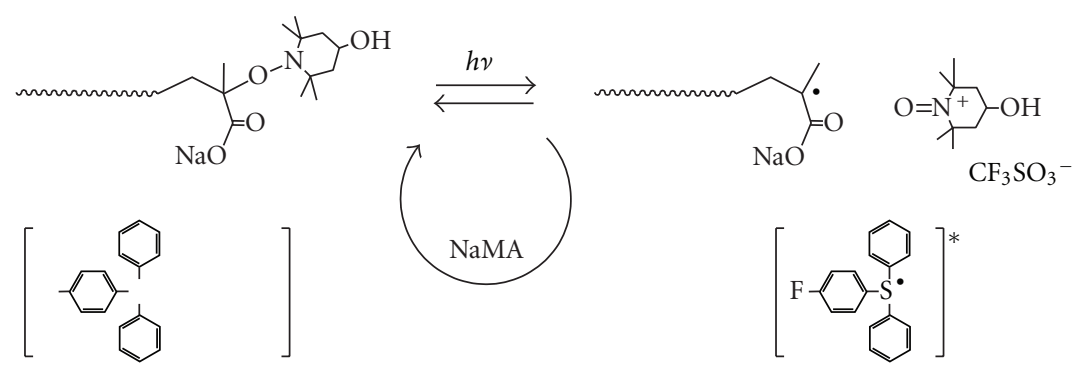

SCHEME 2: The mechanism of the HTEMPO-mediated photopolymerization of NaMA in the presence of V-80 and FS.

\section{Experimental}

2.1. Instrumentation. The photopolymerization was carried out using an Ushio optical modulex BA-H502, an illuminator OPM2-502H with a high-illumination lens UI-OP2SL, and a $500 \mathrm{~W}$ super high-pressure UV lamp (USH-500SC2, Ushio Co., Ltd.). Gel permeation chromatography (GPC) was performed using a Tosoh GPC-8020 instrument equipped with a DP-8020 dual pump, a CO-8020 column oven, and an RI-8020 refractometer. Two gel columns, Tosoh TSK-GEL $\alpha$-M, were used with a mixed solvent $(80 \%$ aqueous solution $\left(0.01 \mathrm{M} \mathrm{Na}_{2} \mathrm{HPO}_{4}\right.$ and $0.05 \mathrm{M} \mathrm{NaNO}_{3}$ ) and $20 \%$ acetonitrile) as the eluent at $40^{\circ} \mathrm{C}$. The molecular weight and molecular weight distribution (MWD) of the resulting polymers were estimated by GPC based on PNaMA standards. 
TABLE 1: The photopolymerization of NaMA in water.

\begin{tabular}{|c|c|c|c|c|c|c|c|}
\hline Run no. & $\mathrm{V}-80(\mathrm{mM})$ & HTEMPO (mM) & $\mathrm{FS}(\mathrm{mM})$ & Time (h) & Conversion (\%) & $M n^{\mathrm{a}}$ & $M w / M n^{\mathrm{a}}$ \\
\hline 1 & - & - & - & 1 & 98 & 208,000 & 29.36 \\
\hline 2 & 44.8 & - & - & 1 & 100 & 86,800 & 10.66 \\
\hline 3 & - & - & 25.3 & 1 & 95 & 202,000 & 46.27 \\
\hline 4 & 44.8 & - & 25.3 & 1 & 98 & 93,800 & 15.04 \\
\hline 5 & 44.8 & 47.6 & - & 6 & 61 & 101,000 & 3.19 \\
\hline 6 & - & 47.6 & 25.3 & 5 & 53 & 52,500 & 2.36 \\
\hline 7 & 44.8 & 47.6 & 25.3 & 9 & 78 & 60,400 & 2.05 \\
\hline 8 & 44.8 & 95.2 & 25.3 & 5 & 0 & - & - \\
\hline 9 & 44.8 & 47.6 & 50.6 & 5 & 55 & 65,700 & 2.58 \\
\hline 10 & 8.96 & 9.52 & 5.06 & 20 & $92^{\mathrm{b}}$ & 20,300 & 3.71 \\
\hline
\end{tabular}

$[\mathrm{NaMA}]_{0}=9.25 \mathrm{mM}$.

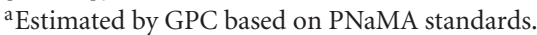

$\mathrm{b}[\mathrm{NaMA}]_{0}=1.85 \mathrm{mM}$.

TABLE 2: The HTEMPO-mediated polymerization of NaMA by V80.

\begin{tabular}{lcccc}
\hline V-80 $(\mathrm{mM})$ & Time $(\mathrm{h})$ & Conversion $(\%)$ & $M n^{\mathrm{a}}$ & $M w / M n^{\mathrm{a}}$ \\
\hline 14.9 & 3.5 & 71 & 86,700 & 2.22 \\
22.5 & 5 & 76 & 75,800 & 2.16 \\
44.8 & 9 & 78 & 60,400 & 2.05 \\
\hline
\end{tabular}

$[\mathrm{NaMA}]_{0}=9.25 \mathrm{mM}, \mathrm{HTEMPO} / \mathrm{V}-80=1.06, \mathrm{FS} / \mathrm{HTEMPO}=0.53$.

${ }^{a}$ Estimated by GPC based on PNaMA standards.

2.2. Materials. V-80 was purchased from Wako Chemicals and used as received. HTEMPO was prepared as reported previously [25]. FS and NaMA were purchased from SigmaAldrich and used as received. Distilled water was purchased from Wako Chemicals and used without further purification.

2.3. Photopolymerization. General procedure NaMA (1 g, $9.25 \mathrm{mmol}), \quad \mathrm{V}-80 \quad(18.3 \mathrm{mg}, 0.0448 \mathrm{mmol})$, HTEMPO $(8.2 \mathrm{mg}, 0.0440 \mathrm{mmol})$, FS (10.9 mg, $0.0253 \mathrm{mmol})$, and distilled water $(1 \mathrm{~mL})$ were placed in an ampoule. After degassing the contents, the ampoule was sealed under vacuum. The polymerization was carried out at room temperature for $9 \mathrm{~h}$ by irradiation with a $500 \mathrm{~W}$ highpressure mercury lamp. Distilled water $(10 \mathrm{~mL})$ was added to the product to dissolve it completely. A small amount of the resulting solution $(0.1 \mathrm{~mL})$ was withdrawn to determine the monomer conversion by ${ }^{1} \mathrm{H}$ NMR. The residual solution was dried in vacuo for several hours to obtain a polymer (1.2441 g).

\section{Results and Discussion}

The photoradical polymerization of NaMA was performed in water using HTEMPO as the mediator, V-80 as the initiator, and a water-soluble photo-acid generator, FS, as the accelerator at room temperature by irradiation (Scheme 1). The results of the polymerization are listed in Table 1. The monomer conversion was estimated by ${ }^{1} \mathrm{H}$ NMR using the signal intensity of the methyl protons at $1.85 \mathrm{ppm}$ for unreacted NaMA and the methyl and methylene protons at $0.6-2.2 \mathrm{ppm}$ for the polymer main chain (Figure 1). The NaMA had a high reactivity for radical polymerizations and caused autopolymerization that produced a very highmolecular-weight polymer with a broad MWD. The polymerization was also initiated by $\mathrm{V}-80$ and yielded a polymer with a lower molecular weight and MWD. Furthermore, the polymerization by FS caused an increase in the MWD. On the other hand, the polymerization using HTEMPO as the mediator significantly decreased the MWD. This HTEMPOmediated polymerization produced a still lower MWD using both $\mathrm{V}-80$ and FS than the polymerization in the presence of either V-80 or FS. The HTEMPO-mediated polymerization is decelerated due to the control of the propagating radials by HTEMPO. Hence, the autopolymerization competitively occurs during the slow polymerization initiated only by $\mathrm{V}-80$, resulting in the higher MWD. Figure 2 shows GPC profiles of the PNaMA obtained by the polymerization in the absence and presence of HTEMPO. The doubling amount of HTEMPO obstructed the polymerization process. An excess of HTEMPO hinders the cleavage of the C-ON bond at the propagating polymer chain end. It has been reported that the PAG accelerated the polymerization of MMA without an increase in the MWD $[14,18,21]$. However, the doubling amount of FS rather caused broadening of the MWD. It is considered that the propagating radicals are much freer in the aqueous medium by the interaction of the water-soluble HTEMPO and FS in the excited state. The proposal mechanism of the HTEMPO-mediated polymerization is shown in Scheme 2. In addition, the dilution of the polymerization system caused a further increase in the MWD.

In order to confirm the living nature of the polymerization, the first-order time-conversion plots were evaluated under the conditions at the HTEMPO/V-80 molar ratio of 1.06 and FS/HTEMPO of 0.53 . The yellow solution gave rise to polymer precipitates after $2.5 \mathrm{~h}$ of the polymerization. Figure 3 shows the time-conversion and its first-order plots for the polymerization. $[\mathrm{M}]$ denotes the monomer concentration. The induction period was observed up to $2.5 \mathrm{~h}$. This induction period can be accounted for by the capture of the initiator radicals generated from V-80 by HTEMPO during the initial stage of the polymerization. The $\ln \left([M]_{0} /[M]_{t}\right)$ 


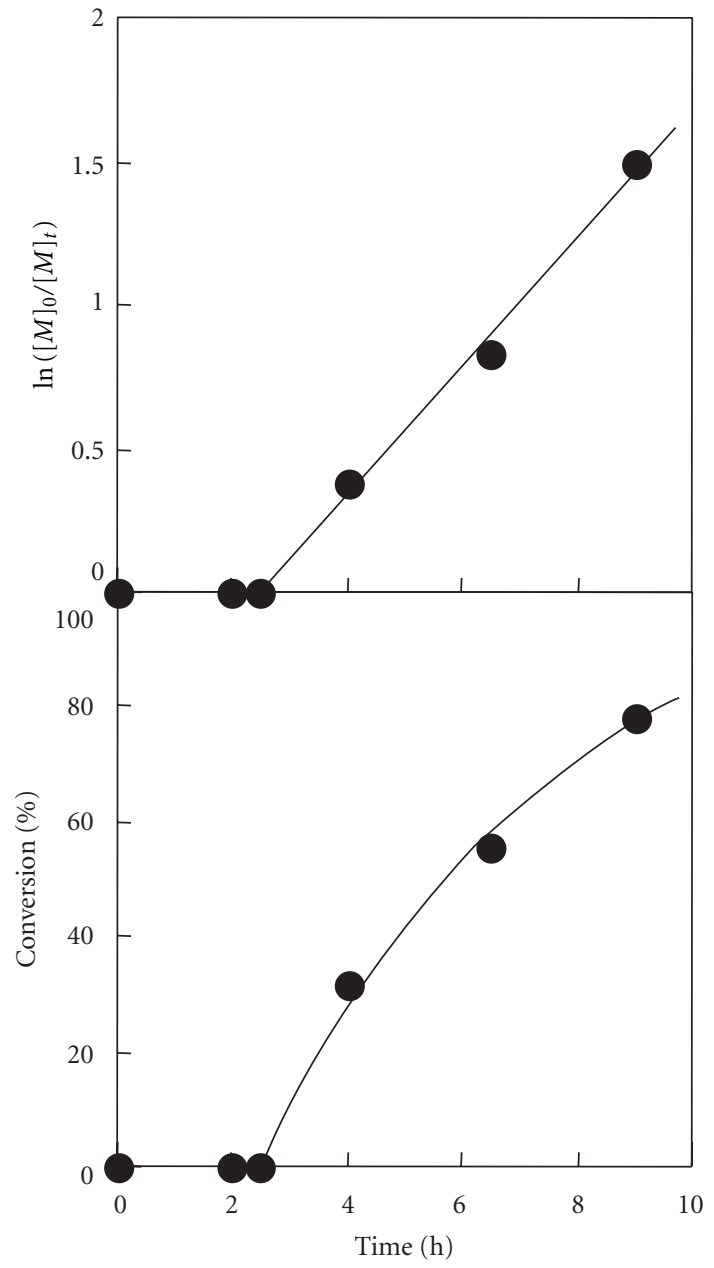

FIGURE 1: The ${ }^{1} \mathrm{H}$ NMR spectrum of the resulting mixture obtained by the HTEMPO-mediated photopolymerization of NaMA in water at HTEMPO/V-80 of 1.06 and HTEMPO/FS of 0.53 . Solvent: $\mathrm{D}_{2} \mathrm{O}$. Conversion $=78 \%$.

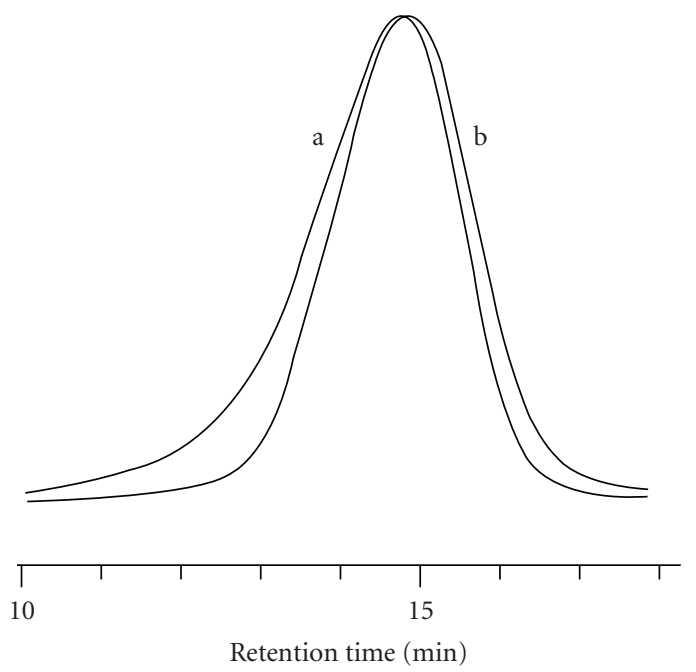

Figure 2: GPC profiles of the PNaMA obtained by the photopolymerization in the absence (a, Table 1, Run 4) and presence (b, Table 1, run 7) of HTEMPO.

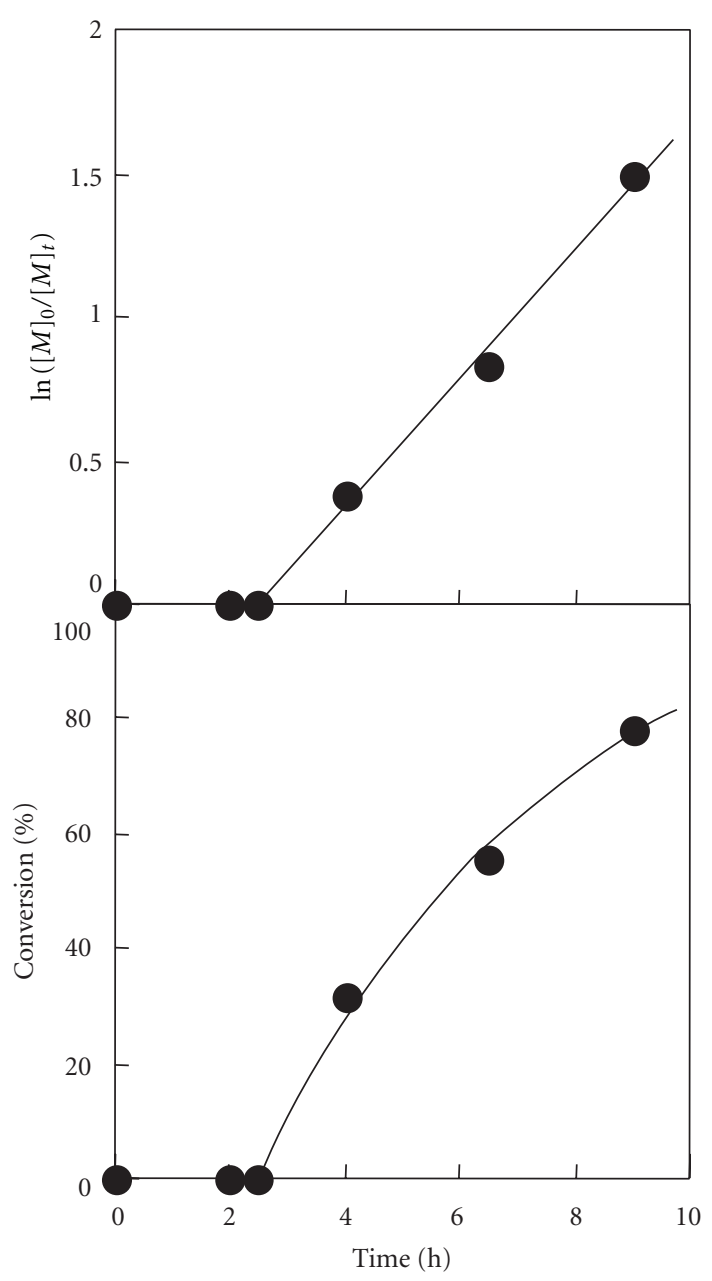

Figure 3: The time conversion and its first-order plots for the NaMA polymerization. HTEMPO/V-80 $=1.06, \mathrm{HTEMPO} / \mathrm{FS}=$ 0.53 .

linearly increased over $2.5 \mathrm{~h}$, indicating that the number of polymer chains was constant throughout the course of the polymerization. The relationship between the conversion and the molecular weight of the polymer revealed the living polymerization. The conversion-molecular weight plots are shown in Figure 4. The observed molecular weight exhibited a linear increase with the increasing conversion. However, the observed molecular weights were in poor agreement with the theoretical values. This poor agreement suggested the low initiator efficiency and the existence of the nonsteady state during the very early stage of the polymerization. The MWD was constant around $M w / M n=2.0$. The MWD is broad when the controlled polymerization is taken into consideration. This broad MWD is due to the fact that the polymers precipitated during the polymerization even at the $32 \%$ conversion. The GPC analysis endorsed the living nature of the polymerization. Figure 5 shows the GPC profiles of the polymers produced for each conversion. The curves were shifted to the higher molecular weight side with an increase in the conversion. 


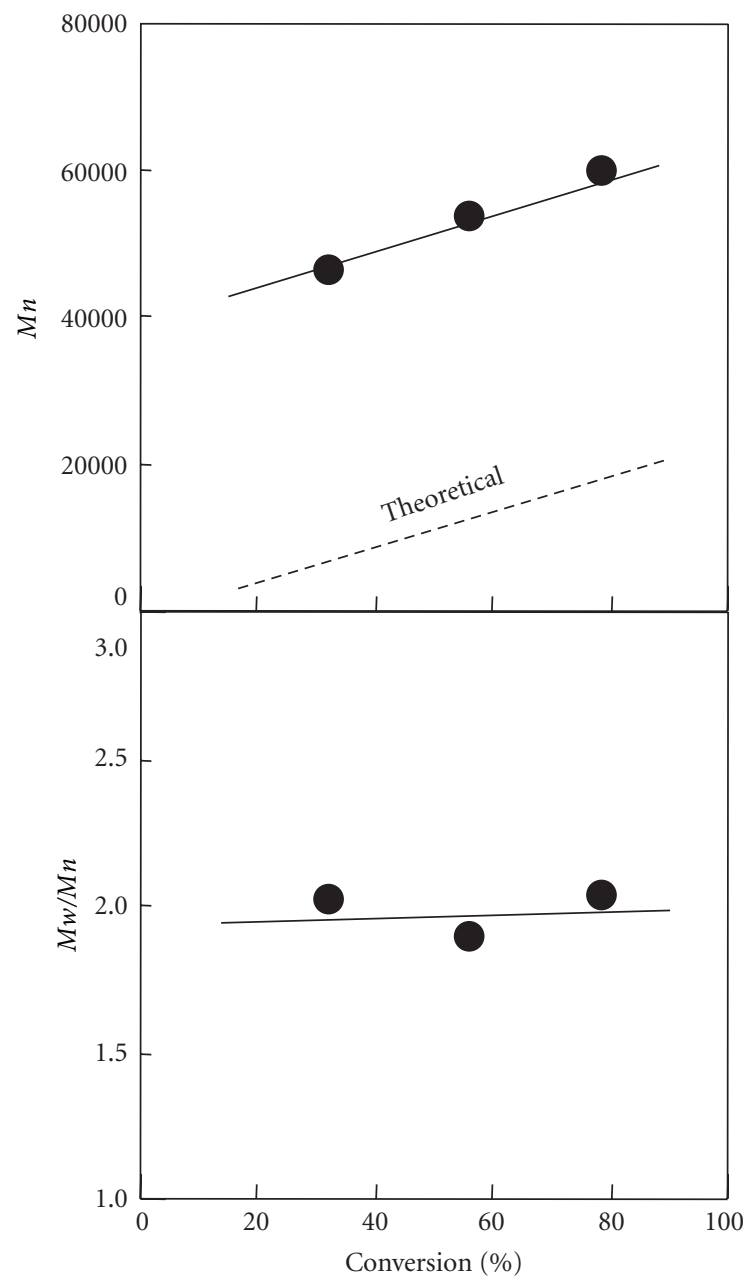

FIgUre 4: The plots of the molecular weight and its distribution versus the conversion for the polymerization. HTEMPO/V-80 = 1.06, $\mathrm{HTEMPO} / \mathrm{FS}=0.53$.

The livingness of the polymerization was also confirmed on the basis of the correlation between the initial concentration of the initiator and the molecular weight of the polymer. Table 2 shows the results on the HTEMPOmediated polymerization at three different concentrations of $\mathrm{V}$-80. The molecular weight decreased with an increase in the initiator concentration, while the MWD was constant at ca. 2. The plotted molecular weight versus the reciprocal of the initial concentration of V-80 showed a linear increase in the molecular weight (Figure 6). Therefore, it can be deduced that the HTEMPO-mediated photoradical polymerization of NaMA in water proceeded by a living mechanism using V-80 and FS.

\section{Conclusion}

The photo-living radical polymerization of NaMA was attained in an aqueous solution using the HTEMPO mediator in the presence of $\mathrm{V}-80$ and FS. The polymerization produced polymers with an MWD around $M w / M n=2$. This somewhat broad MWD was attributed to the precipitation

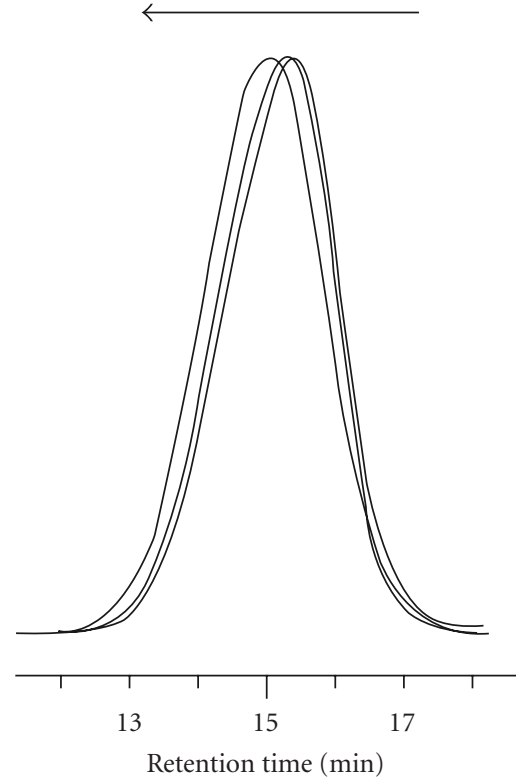

FIgURE 5: The variation in the GPC curves versus the conversion: $32 \%(4 \mathrm{~h}), 56 \%(6.5 \mathrm{~h})$, and $78 \%(9 \mathrm{~h})$ from the right.

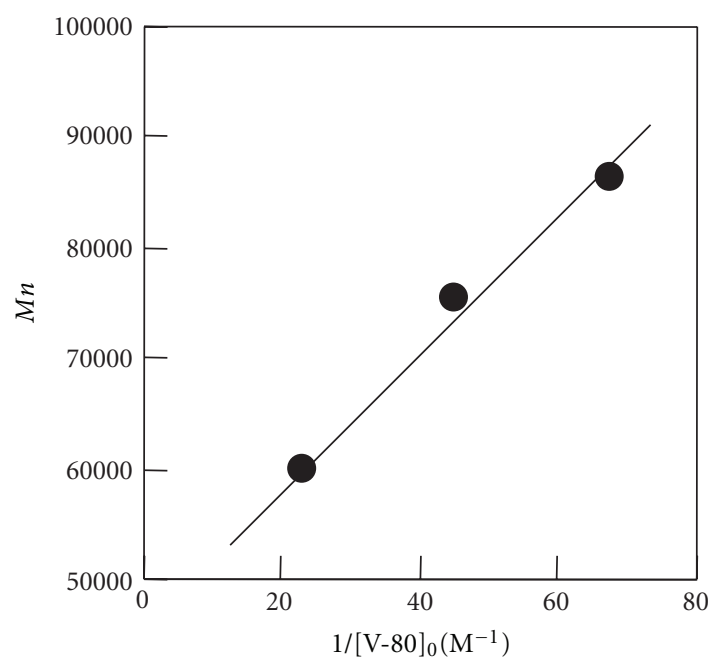

FIGURE 6: The plots of the molecular weight and its distribution versus the reciprocal of the initiator concentration for the polymerization. HTEMPO/V-80 $=1.06, \mathrm{HTEMPO} / \mathrm{FS}=0.53$.

of the polymers during the polymerization. The first-order time-conversion plots included an induction period up to $2.5 \mathrm{~h}$; however, They thereafter showed a linear increase. The conversion-molecular weight plots also exhibited a linear increase, although the observed molecular weights were in poor agreement with the theoretical values due to the low initiator efficiency and the nonsteady state during the very early stage of the polymerization. Furthermore, a linear increase was obtained for the plots of the molecular weight versus the reciprocal of the initiator concentration. Based on these three linear correlations, it can be deduced that the HTEMPO-mediated photoradical polymerization of NaMA proceeded in accordance with a living mechanism. 


\section{References}

[1] J. Higashi, Y. Nakayama, R. E. Marchant, and T. Matsuda, "High-spatioresolved microarchitectural surface prepared by photograft copolymerization using dithiocarbamate: surface preparation and cellular responses," Langmuir, vol. 15, no. 6, pp. 2080-2088, 1999.

[2] F. Zhang, Z. Zhang, X. Zhu, E. T. Kang, and K. G. Neoh, "Silkfunctionalized titanium surfaces for enhancing osteoblast functions and reducing bacterial adhesion," Biomaterials, vol. 29, no. 36, pp. 4751-4759, 2008.

[3] T. Cao, P. Munk, C. Ramireddy, Z. Tuzar, and S. E. Webber, "Fluorescence studies of amphiphilic poly(methacrylic acid)block-polystyrene-block-poly(methacrylic acid) micelles," Macromolecules, vol. 24, no. 23, pp. 6300-6305, 1991.

[4] D. Kiserow, K. Prochazka, C. Ramireddy, Z. Tuzar, P. Munk, and S. E. Webber, "Fluorimetric and quasi-elastic light scattering study of the solubilization of nonpolar low-molar mass compounds into water-soluble block-copolymer micelles," Macromolecules, vol. 25, no. 1, pp. 461-469, 1992.

[5] J. Chan, S. Fox, D. Kiserow, C. Ramireddy, P. Munk, and S. E. Webber, "Time-resolved fluorescence depolarization studies of naphthalene-labeled diblock copolymer micelles in aqueous media," Macromolecules, vol. 26, no. 25, pp. 7016-7023, 1993.

[6] M. Tian, A. Qin, C. Ramireddy et al., "Hybridization of block copolymer micelles," Langmuir, vol. 9, no. 7, pp. 1741-1748, 1993.

[7] S. Creutz, J. Van Stam, S. Antoun, F. C. De Schryver, and R. Jérôme, "Exchange of polymer molecules between block copolymer micelles studied by emission spectroscopy. A method for the quantification of unimer exchange rates," Macromolecules, vol. 30, no. 14, pp. 4078-4083, 1997.

[8] E. J. Ashford, V. Naldi, R. O’Dell, N. C. Billingham, and S. P. Armes, "First example of the atom transfer radical polymerisation of an acidic monomer: direct synthesis of methacrylic acid copolymers in aqueous media," Chemical Communications, no. 14, pp. 1285-1286, 1999.

[9] V. L. Osborne, D. M. Jones, and W. T. S. Huck, "Controlled growth of triblock polyelectrolyte brushes," Chemical Communications, vol. 8, no. 17, pp. 1838-1839, 2002.

[10] F. Zhou, Z. Zheng, B. Yu, W. Liu, and W. T. S. Huck, "Multicomponent polymer brushes," Journal of the American Chemical Society, vol. 128, no. 50, pp. 16253-16258, 2006.

[11] S. Tugulu, R. Barbey, M. Harms et al., "Synthesis of poly(methacrylic acid) brushes via surface-initiated atom transfer radical polymerization of sodium methacrylate and their use as substrates for the mineralization of calcium carbonate," Macromolecules, vol. 40, no. 2, pp. 168-177, 2007.

[12] H. J. Lee, Y. Nakayama, and T. Matsuda, "Spatio-resolved, macromolecular architectural surface: highly branched graft polymer via photochemically driven quâsiliving polymerization technique," Macromolecules, vol. 32, no. 21, pp. 69896995, 1999.

[13] E. Yoshida, "Photo-living radical polymerization of methyl methacrylate by a nitroxide mediator," Colloid \& Polymer Science, vol. 286, no. 14-15, pp. 1663-1666, 2008.

[14] E. Yoshida, "Photo-living radical polymerization of methyl methacrylate by 2,2,6,6-tetramethylpiperidine-1-oxyl in the presence of a photo-acid generator," Colloid \& Polymer Science, vol. 287, no. 7, pp. 767-772, 2009.

[15] E. Yoshida, "Synthesis of poly(methyl methacrylate)-blockpoly(tetrahydrofuran) by photo-living radical polymerization using a 2,2,6,6-tetramethylpiperidine-1-oxyl macromediator," Colloid \& Polymer Science, vol. 287, no. 12, pp. 1417-1424, 2009.

[16] E. Yoshida, "Photo-living radical polymerization of methyl methacrylate using alkoxyamine as an initiator," Colloid \& Polymer Science, vol. 288, no. 1, pp. 7-13, 2010.

[17] E. Yoshida, "Effect of azoinitiators on nitroxide-mediated photo-living radical polymerization of methyl methacrylate," Colloid \& Polymer Science, vol. 288, no. 3, pp. 341-345, 2010.

[18] E. Yoshida, "Nitroxide-mediated photo-living radical polymerization of methyl methacrylate using (4-tert-butylphenyl)diphenyl-sulfonium triflate as a photo-acid generator," Colloid \& Polymer Science, vol. 288, no. 2, pp. 239-243, 2010.

[19] E. Yoshida, "Effects of initiators and photo-acid generators on nitroxide-mediated photo-living radical polymerization of methyl methacrylate," Colloid \& Polymer Science, vol. 288, no. 8, pp. 901-905, 2010.

[20] E. Yoshida, "Stability of growing polymer chain ends for nitroxide-mediated photo-living radical polymerization," Colloid \& Polymer Science, vol. 288, no. 9, pp. 1027-1030, 2010.

[21] E. Yoshida, "Nitroxide-mediated photo-living radical polymerization of methyl methacrylate in solution," Colloid \& Polymer Science, vol. 288, no. 16-17, pp. 1639-1643, 2010.

[22] E. Yoshida, "Graft copolymerization of methyl methacrylate on polystyrene backbone through nitroxide-mediated photoliving radical polymerization," Colloid \& Polymer Science, vol. 289, no. 7, pp. 837-841, 2011.

[23] E. Yoshida, "Nitroxide-mediated photo-living radical polymerization of methyl methacrylate in the presence of ( $\eta^{6}$-benzene) $\left(\eta^{5}\right.$-cyclopentadienyl)Fe $\mathrm{F}^{\mathrm{II}}$ hexafluorophosphate," Colloid \& Polymer Science, vol. 288, no. 18, pp. 1745-1749, 2010.

[24] E. Yoshida, "Nitroxide-mediated photo-controlled/living radical dispersion polymerization of methyl methacrylate," Colloid \& Polymer Science, vol. 289, no. 14, pp. 1625-1630, 2011.

[25] T. Kurosaki, K. W. Lee, and M. Okawara, "Polymers having stable radicals. I. Synthesis of nitroxyl polymers from 4-methacryloyl derivatives of 2,2,6,6-tetramethylpiperidine," Journal of Polymer Science Part A-1, vol. 10, no. 11, pp. 32953310, 1972. 

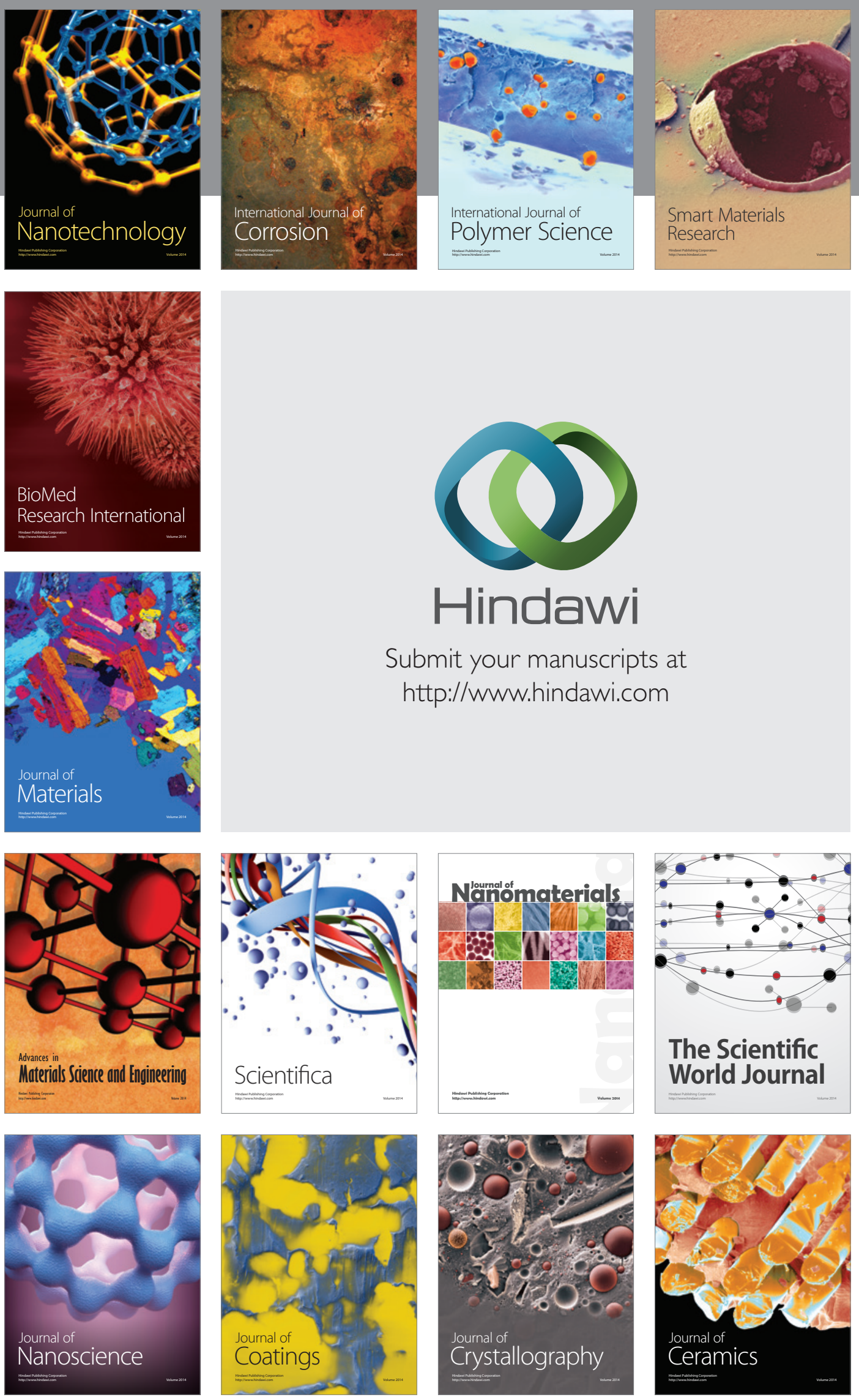

The Scientific World Journal

Submit your manuscripts at

http://www.hindawi.com

\section{World Journal}

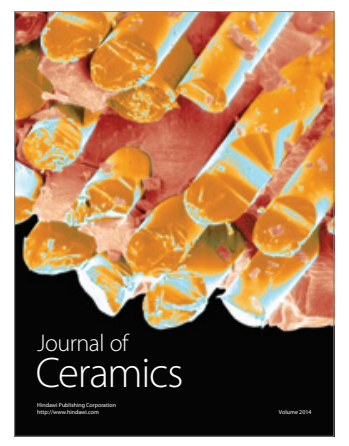

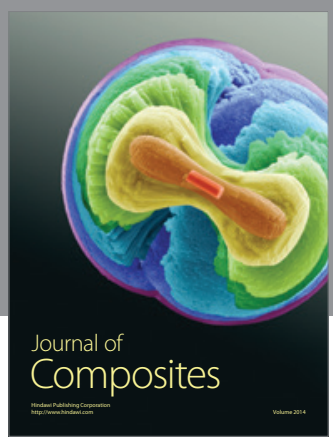
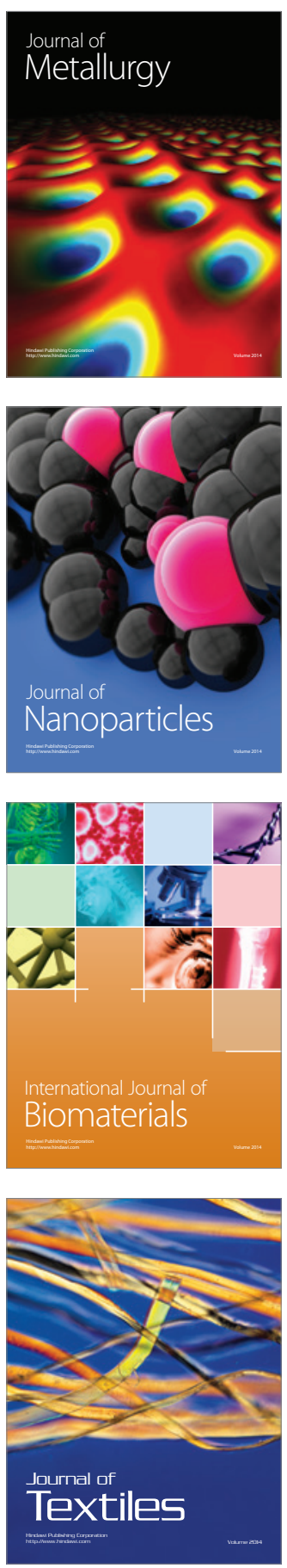